\title{
TREE-RING BASED TEMPERATURE RECONSTRUCTION FOR THE WEST QINLING MOUNTAINS (CHINA): LINKAGES TO THE HIGH ASIA, SOLAR ACTIVITY AND PACIFIC-ATLANTIC OCEAN
}

\author{
FENG CHEN ${ }^{1,2}$, YUJIANG YUAN ${ }^{1,2}$, WENSHOU WEI ${ }^{1,2}$, SHULONG YU $^{1,2}$, HUAMING SHANG $^{1,2}$, \\ TONGWEN ZHANG ${ }^{1,2}$, RUIBO ZHANG ${ }^{1,2}$, HUIQIN WANG ${ }^{3}$ and LI QIN ${ }^{1,2}$ \\ ${ }^{1}$ Key Laboratory of Tree-ring Physical and Chemical Research of China Meteorological Administration, Institute of Desert \\ Meteorology, China Meteorological Administration, No 46 Jianguo Road, Urumqi 830002, China \\ ${ }^{2}$ Xinjiang Laboratory of Tree Ring Ecology, Institute of Desert Meteorology, China Meteorological Administration, \\ No 46 Jianguo Road, Urumqi 830002, China \\ ${ }^{3}$ College of Earth and Environmental Science, Lanzhou University, Lanzhou 73000, China
}

Received 16 July 2013

Accepted 7 March 2014

\begin{abstract}
We developed a Faxon fir (Abies faxoniana) tree-ring width chronology at the timberline in the western Qinling Mountains, China. Herein February-July mean temperature was reconstructed for Zhouqu in the western Qinling Mountains back to AD 1650 based on the standard chronology. The climate/tree-growth model accounts for $43.5 \%$ of the instrumental temperature variance during the period 1972-2006. Spatial correlation analyses with the gridded temperature data shows that the temperature reconstruction captures regional climatic variations over central and southeast China, and strong teleconnections with the nearby High Asia. There is a good agreement with cold and warm periods previously estimated from tree-rings in Nepal, India and southwest China. The temperature reconstruction indicates that there was pronounced cooling in Zhouqu during the Maunder Minimum (late 1600 s to early 1700 s). The cold period (1813-1827) of the temperature reconstruction coincide with the volcanic eruptions. Significant spectral peaks are found at 56.9, 22.3, 11.4, 2.9, 2.8, 2.6, 2.2 and 2.0 years. The spatial correlation patterns between our temperature reconstruction and SSTs of the Atlantic and Pacific Oceans suggest a connection between regional temperature variations and the atmospheric circulations. It is thus revealed that the chronology has enough potential to reconstruct the climatic variability further into the past.
\end{abstract}

Keywords: tree rings, Western Qinling Mountains, Zhouqu, temperature reconstruction, spatial variability, solar activity.

\section{INTRODUCTION}

With their long-term, high resolution and repeatability, tree rings provide one of the best sources of proxy information about climate change. There have been re-

Corresponding author: F. Chen

e-mail: feng653@163.com cent efforts to improve the coverage of dendroclimatic reconstructions in Asia; for example, for India, southwest China, Nepal and Central Asia (i.e. Borgaonkar et al., 1996; Hughes 2001; Cook et al., 2003; Esper, 2002; Bräuning and Mantwill, 2004; Wu et al., 2008; Fan et al., 2009; Duan et al., 2010; Chen et al., 2010). The Monsoon Asia Drought Atlas (MADA) over the past 700 years from tree-rings was presented by Cook et al. 
(2010). However, compared to other continents, such as Europe and North America, the number of tree-ring investigation sites from Asia is relatively low. More chronologies are needed to interpret the past climate variability of Asia over long temporal and large spatial scales.

The annual growth variations of these trees as recorded by the annual rings may record climatic variations that relate to the climate conditions of Qinling Mountains. Many dendroclimatic studies have been carried out in central and east Qinling Mountains and adjacent regions (Hughes et al., 1994; Shao and Wu, 1994; Liu and Shao, 2003; Garfin et al., 2005; Dang et al., 2007; Liu et al., 2009). However, long-term dendroclimatological records still remain a lack in the western Qinling Mountains.

The objectives of this study were: (1) development of a tree-ring width chronology in the western Qinling Mountains, (2) exploration of the relationships between tree growth and climate, (3) reconstruction of past climate changes, (4) cross-validation of our reconstruction with other climatic reconstructions for Nepal, India and southwest China, and (5) spectral analyses and linkages with the ocean climate variability.

\section{DATA AND METHODS}

\section{Study area}

The study area is located in the western Qinling Mountains range in south Gansu, China, where the climate is affected by the Asian Monsoon (Chen et al., 2013) (Fig. 1). At the Zhouqu meteorological station of China Meteorological Administration $\left(33^{\circ} 47^{\prime} \mathrm{N}\right.$, $104^{\circ} 22^{\prime} \mathrm{E}, 1400 \mathrm{~m}$ a.s.l.), January (mean temperature $1.9^{\circ} \mathrm{C}$ ) and July (mean temperature $23.6^{\circ} \mathrm{C}$ ) are the coldest and the warmest months, respectively (Fig. 2). The mean of total annual precipitation is $430 \mathrm{~mm}$ from 1972 to 2006 , with $84 \%$ of the annual precipitation falling

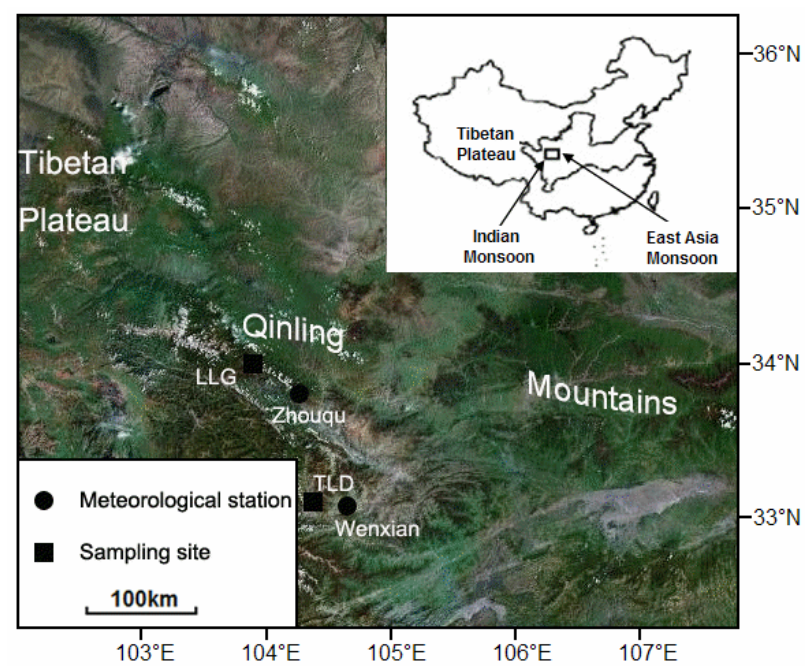

Fig. 1. Location map of sampling sites and meteorological station. during the growing season, approximately from April to September. The mean annual frost-free period is 223 days while the mean relative humidity is $50-55 \%$. Biogeographically, the area is in a transitional zone between the northeast edge of Tibetan Plateau and the Qinling Mountains. The study site is Faxon fir (Abies faxoniana) forests growing on shallow or rocky soils (Fig. 3). Soils are mainly acid umber and podzolic soil.

\section{Chronology development}

During the spring of 2007 (May), a site (LLG) with little evidence of fire or human disturbance at the timberline in Diebu County was chosen (Table 1). The samples were collected along a mountain ridge. The site elevation ranged from $3120 \mathrm{~m}$ to $3200 \mathrm{~m}$. The canopy coverage of the sampled trees was less than $20 \%$ with their height ranging from $15 \mathrm{~m}$ to $25 \mathrm{~m}$. The diameter of the sampled trees at breast height varies between 25 and $40 \mathrm{~cm}$. All trees were sampled non-destructively at breast height using 5-mm-diameter increment borers. Most of trees were sampled with two radii from two directions and some young trees were sampled with one core. In total 38 increment cores were collected from 21 living trees. After air-dried and mounted on the wooden holders, the cores were sanded with progressively finer grit sand paper. Annual ring widths were measured to the nearest $0.001 \mathrm{~mm}$ using a Velmex measuring system. The crossdating of ring widths was checked using the COFECHA program (Holmes, 1983). Each individual ring-width series was standardized with a fixed 100 year spline function in order to remove non-climatic, age-related growth trends (Fritts, 1976), and thus the chronology does not contain low-frequency (much longer than 100-year) variations. Standardization was performed using the ARSTAN program (Cook, 1985). The detrended data from individual tree cores were combined into the site chronology using a bi-weight robust mean to minimize the influence of outliers, extreme values or biases (e.g. from spurious trends) in tree-ring indices (Cook et al., 1990). Sample depth within a chronology typically decreases back in time and may result in time dependent variance changes in the earlier part of the chronology and a weaker common signal (Woodhouse, 2003). Thus, the variance of chronologies was stabilized in the chronology compilation process using the methods outlined by Osborn et al. (1997), which uses average correlations between series in combination with sample depth each year

Table 1. Information about the sampling sites in western Qinling Mountains.

\begin{tabular}{ccccccc}
\hline Site $\begin{array}{c}\text { Latitude } \\
(\mathbf{N})\end{array}$ & $\begin{array}{c}\text { Longitude } \\
(\mathbf{E})\end{array}$ & Tree number & $\begin{array}{c}\text { Elevation } \\
(\mathbf{m})\end{array}$ & \multicolumn{2}{c}{ Aspect Slope } \\
\hline LLG $34^{\circ} 07^{\prime}$ & $103^{\circ} 48^{\prime}$ & 21 & $3120-3200$ & NW & $10-15^{\circ}$ \\
TLD $32^{\circ} 56^{\prime}$ & $104^{\circ} 20^{\prime}$ & 24 & 3150 & SW & $20-50^{\circ}$ \\
\hline
\end{tabular}




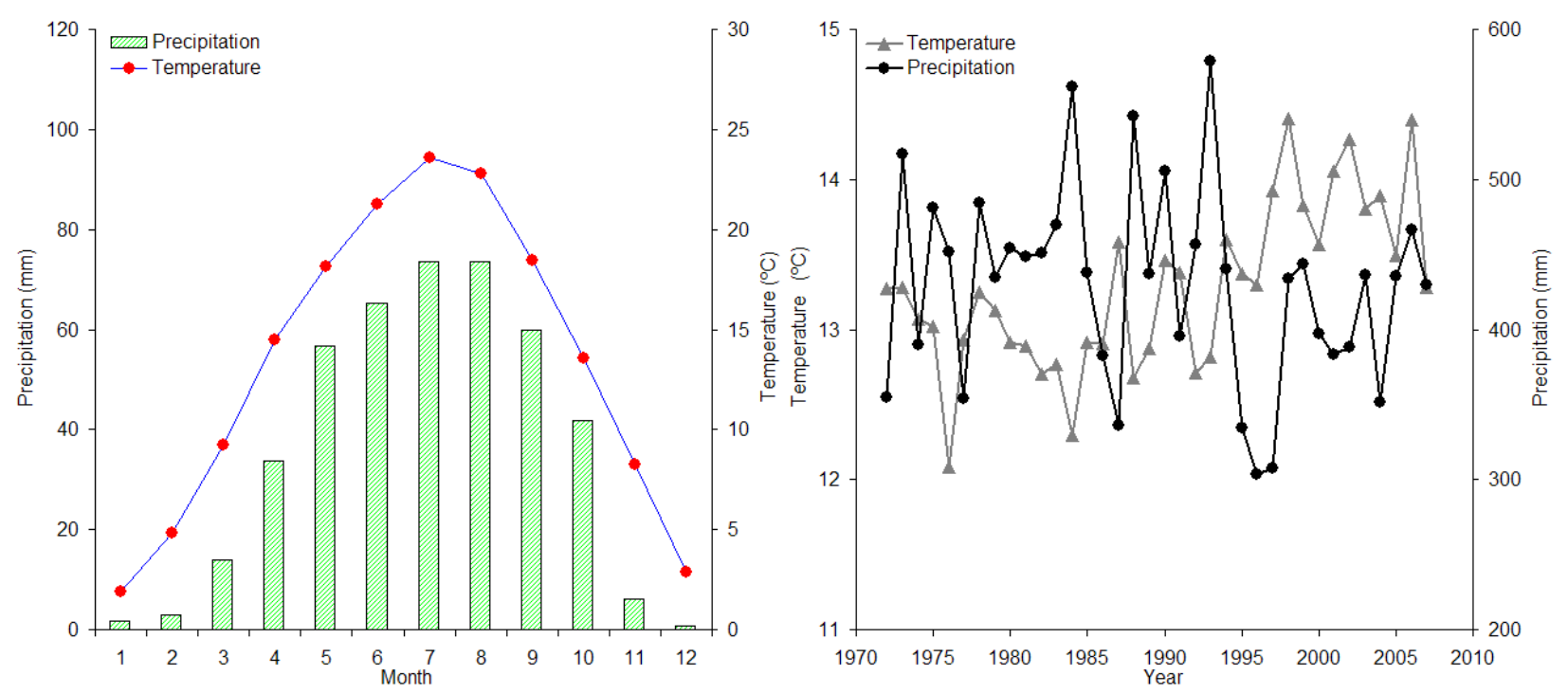

Fig. 2. (a) Climate diagrams for the meteorological station of Zhouqu close to the studied tree-ring sites. Bars indicate monthly precipitation sums and lines monthly average temperature averaged over the period 1972-2006; (b) annual temperature and precipitation data the meteorological station of Zhouqu from 1972 to 2006.

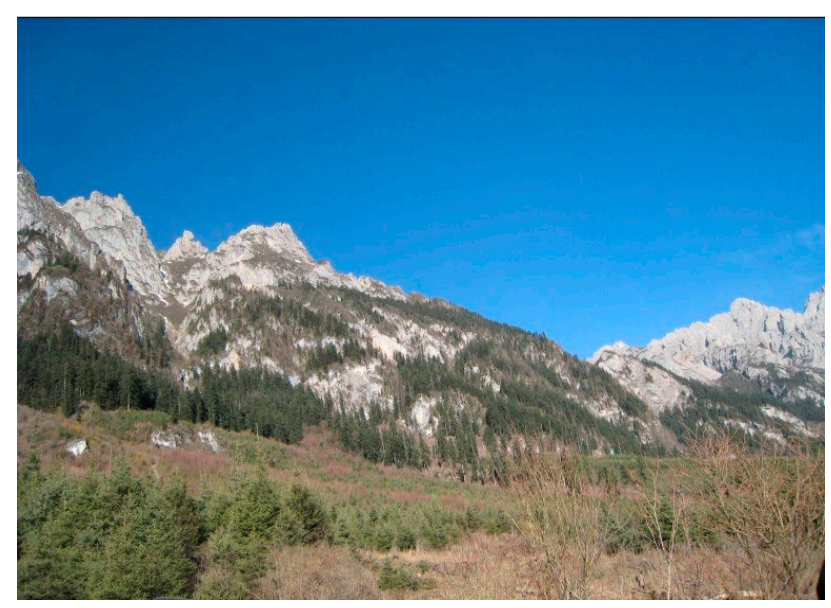

Fig. 3. The timberline site (LLG) in Diebu County, characterized by wide talus slopes and open fir forests.

to make adjustments in the variance for changes in sample depth. The ARSTAN program produces a standard chronology. Expressed population signal (EPS) and the mean inter-series correlation (Rbar) (Wigley et al., 1984) were calculated to determine the statistically reliable time periods of the chronology. A threshold of EPS $>0.85$ was often employed to determine the most reliable period of the chronology.

\section{Statistical analysis}

Monthly records of mean temperature and total precipitation were available from the Zhouqu meteorological station (i.e. 1972 to 2006). During the analysis process, to test the homogeneity of meteorological records of Zhouqu, the standard normal homogeneity test (SNHT; Alexandersson, 1986; Alexandersson and Moberg, 1997) was used. The relationships between tree-ring indices and the climatic data were analyzed using the program DENDROCLIM2002 (Biondi and Waikul, 2004). As the growth of tree may be affected not only by the climatic conditions of the current growing season but also by those of the previous growing season (Fritts, 1976), the climate response analysis was performed over 1972-2006 between the standard chronology and each of the climate data sets from previous July to current September.

Because the climate record is not long enough to be divided into the calibration and verification sections, the leave-one-out cross-validation method was used to test the goodness-of-fit of the model (Blasing et al., 1981). The testing statistics used included the reduction of error (RE), coefficient of efficiency (CE) statistics, the product means test, the sign test, and the Pearson's correlation coefficient (Fritts et al., 1990).

To demonstrate that our record's geographical representation, we conducted spatial correlations between our reconstructed temperature, instrumental temperature and the gridded temperature dataset of CRU TS 3.1 (Mitchell and Jones, 2005) over their overlapping periods from 1901 to 2006 and from 1972 to 2006, respectively. The correlations of regional temperature with the gridded seasurface temperature (SST) dataset of HadISST1 (Rayner et al., 2003) were used to investigate the teleconnections of regional temperature with remote oceans. Correlations were calculated after removing the linear trends of data, by using the detrending option of the KNMI Climate Explorer (http://climexp.knmi.nl). 
The multitaper method (MTM) of spectral analysis (Mann and Lees, 1996) was employed to examine the characteristics of local climate variability in the frequency domain. The analysis was performed over the full range of our reconstruction. Our analysis used $5 \times 3 \pi$ tapers and in a red noise background. The wavelet coherence analysis (Torrence and Compo, 1998) was used to analyze the relationships between annual sunspot number records and temperature reconstruction.

\section{RESULTS}

\section{Chronology}

The mean sensitivity (MS: 0.115) and standard deviations (SD: 0.219) of the chronology are small (Table 2), indicating rather moderate inter-annual variations in the ring-width series, which is characteristic for trees growing in humid environments. Mean correlation with master series is 0.51 . The correlation coefficients are significant at the $1 \%$ level by using the significance test based on a Monte Carlo technique (Preisendorfer, 1988). The first-

Table 2. Statistics of standard ring width chronology.

\begin{tabular}{ccccccc}
\hline SD & MS & SNR & R & EPS & VFE & AC1 \\
\hline 0.219 & 0.115 & 14.315 & 0.51 & 0.935 & $43.00 \%$ & 0.762 \\
\hline \multicolumn{8}{c}{ SD - standard deviation, MS } & - mean sensitivity, SNR - signal to \\
noise ratio; $R$ & - mean correlation with the master series, \\
EPS - agreement with population chronology, VFE - variance in first \\
eigenvector, AC1 - first-order autocorrelation
\end{tabular}

order autocorrelation $(\mathrm{AC} 1)$ is 0.762 . This implies that conditions that cause a ring to be narrow (or wide) in one year tend to carry over their effect on the growth of the following year. In addition, SNR (signal to noise ratio: 14.315), EPS (agreement with population chronology: 0.935 ) and VFE (the variance in first eigenvector: $43.00 \%$ ) are high, indicating that the chronology contained the strong common signals and was suitable to dendroclimatic research.

The running mean EPS ranged from 0.822 to 0.963 (Fig. 4). The mean $R_{\text {bar }}$ for ring width is 0.377 . Although the EPS value of $1676-1700(0.822)$ is lower than 0.85 , there are still seven series from the four trees. Thus, the chronology used in the final reconstruction below was truncated prior to $\mathrm{AD} 1650$ that the retained periods contained at least 3 trees and 5 cores.

\section{Tree growth-climate relationships}

Fig. 5 depicts the results of response function and simple correlation analysis for 1972-2006. Correlations between the ring width and temperatures reveal significant $(p<0.05)$ response to previous year July and September, current year February-April and June-September (positive). The ring width does not correlate significantly with precipitation of any month. As seasonally averaged temperature is more representative of temperature condition than just one single month, we further explored the appropriate season for reconstruction. The strongest correlation was found between the standard chronology and February-July mean temperature $(r=0.66 ; p<0.001)$. Therefore, February-July was used as the temperature reconstruction season.

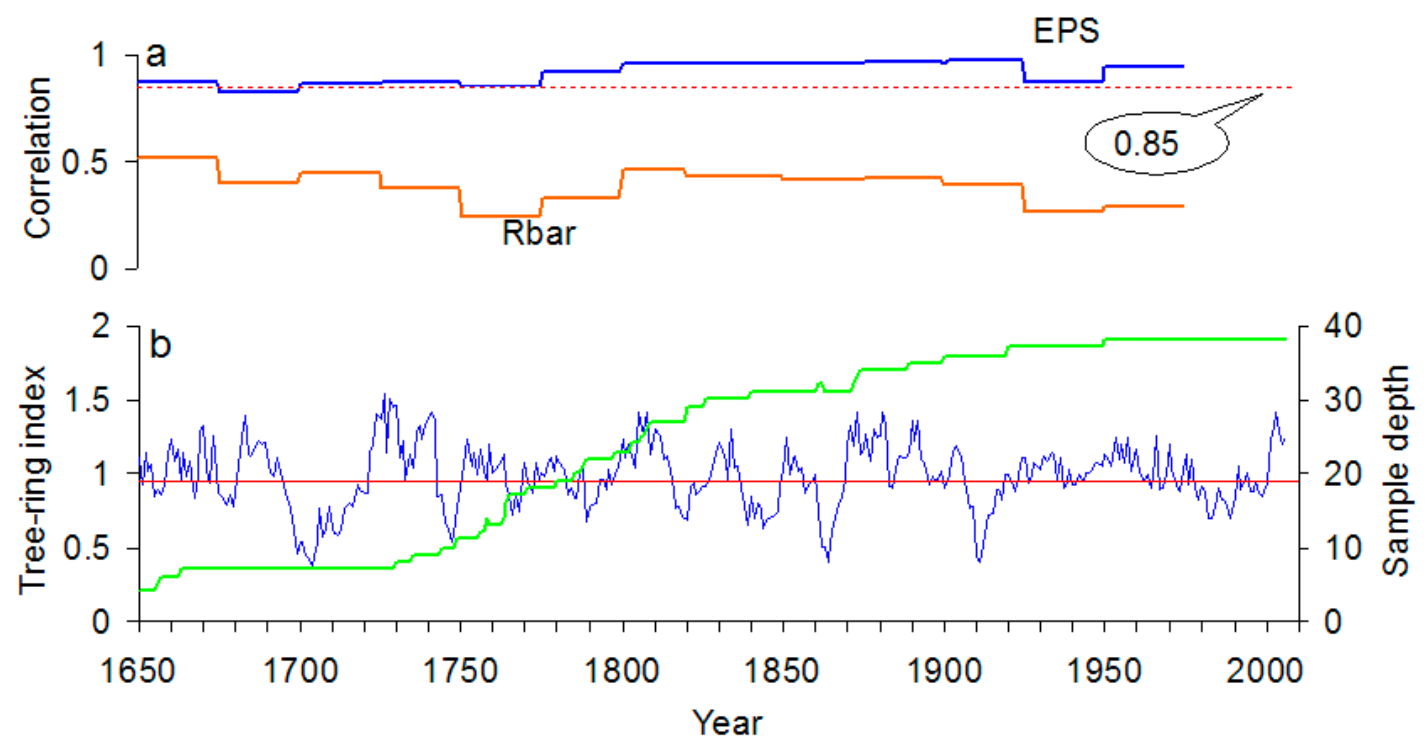

Fig. 4. (a) EPS and Rbar statistics (calculated over 50 years lagged by 25 years) of (b) the chronology (AD 1650-2006) after variance adjustment. The horizontal dashed line denotes the 0.85 EPS criterion for signal strength acceptance. 

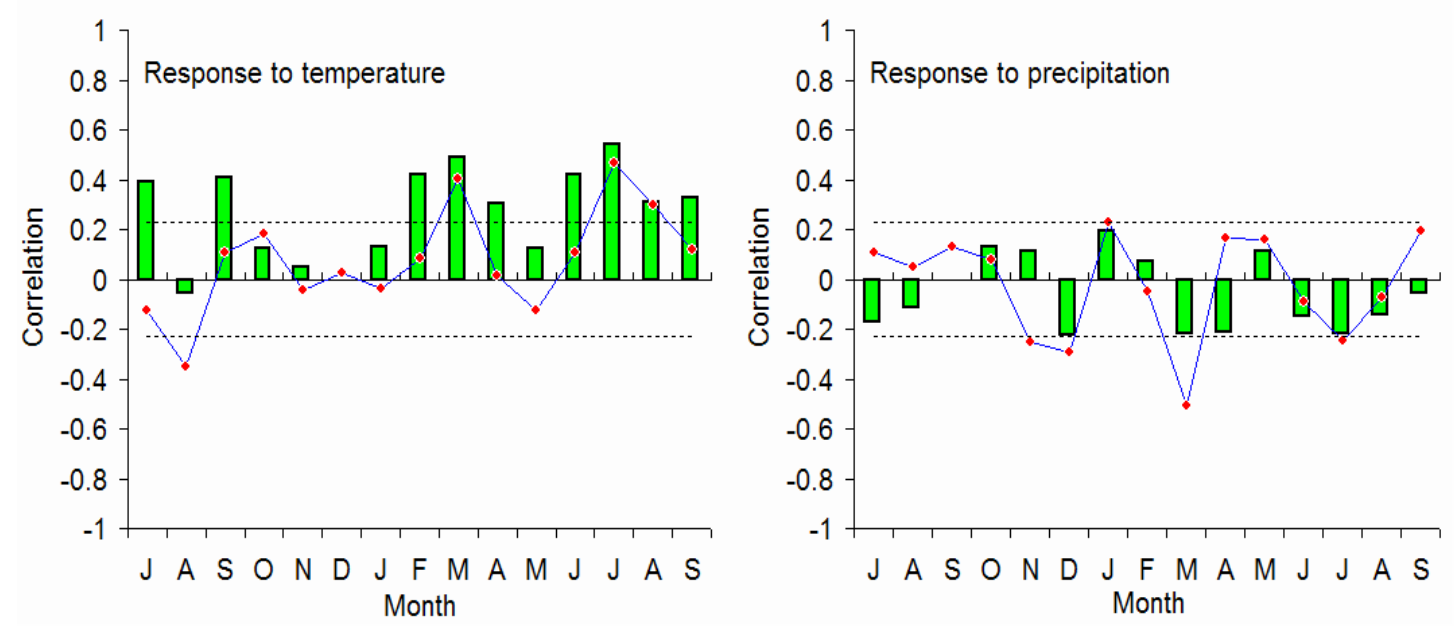

Fig. 5. Climate response of ring width of Abies faxoniana from the LLG site in West Qinling Mountains, using mean temperatures (bars), precipitation sums (bars) and their first difference (lines). The dotted lines indicate the 95\% significance level.

\section{Temperature reconstruction}

Based on the above correlation analysis results, a linear regression model was employed in our study to perform the reconstruction. The model accounts for $43.5 \%$ of the actual temperature variance during 1972 to 2006 . The model obtained was:

$Y=2.619 X-12.742$

where $Y$ is February-July mean temperature $\left({ }^{\circ} \mathrm{C}\right)$ and $X$ is ring width index. The values of the reduction of error (RE), the coefficient of efficiency (CE) and the product means test (PMT) are both positive, which indicates significant skill in the tree-ring estimates (Table 3). The results of the sign test, which describes how well the predicted value tracks the direction of actual data, exceed the $95 \%$ confidence level. These test results demonstrate
Table 3. Leave-one-out cross-validation statistics for the reconstruction of February-July temperature in Zhouqu.

\begin{tabular}{ccccc}
\hline $\mathbf{r}$ & $\mathrm{aR}^{2}$ & $\mathbf{S T}$ & $\mathrm{RE} / \mathrm{CE}$ & PMT \\
\hline 0.660 & 0.418 & $24^{+} / 11^{-}$ & $0.382 / 0.382$ & 2.816 \\
\hline
\end{tabular}

$\mathrm{r}$ - correlation coefficient, $\mathrm{aR}^{2}$ - explained variance after adjustment for degrees of freedom, RE - reduction of error statistic, CE - coefficient of efficiency statistic, ST — results of a sign test, PMT — the product means test

the validity of our regression model. The February-July temperature estimates derived from this model agreed well with the original temperature curve, except for some years with extraordinary high temperatures (Fig. 6). On the basis of this model, the temperature history of Zhouqu has been reconstructed for the period AD 1650-2006.
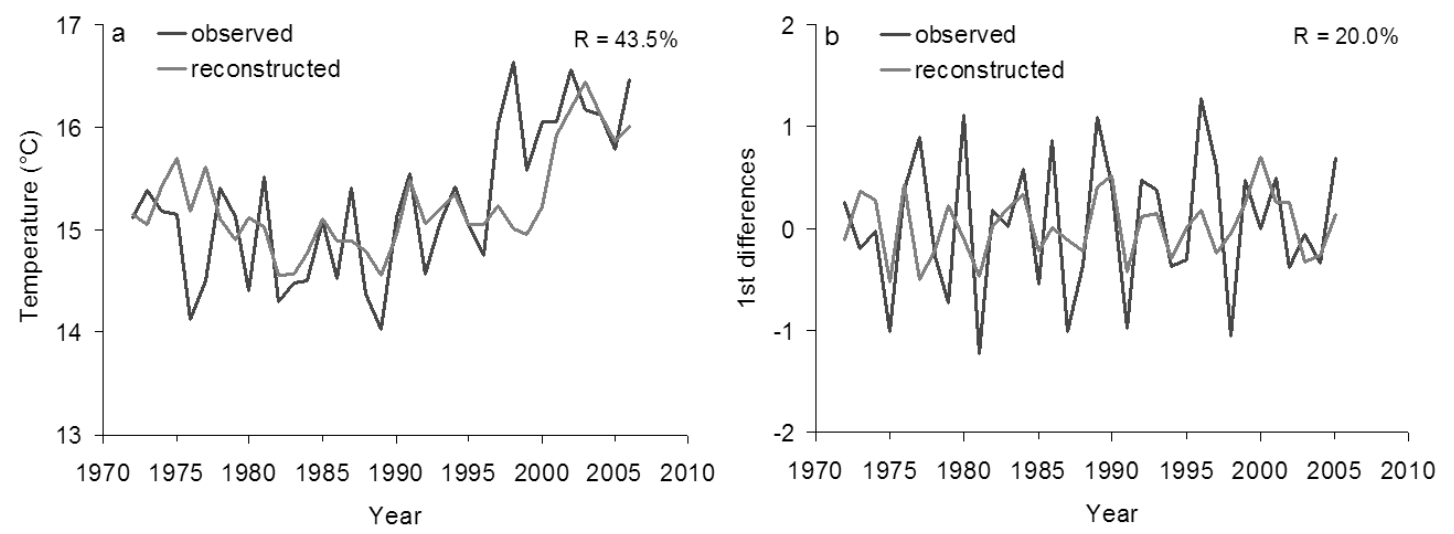

Fig. 6. (a) Comparison between the instrumental and reconstructed mean February-July temperature for their common period 1972-2006. (b) Comparison between the first differences (year-to-year changes) of instrumental and reconstructed mean February-July temperature for their common period 1972-2006. 


\section{Temperature variations from 1650 to 2006 AD for the west Qinling Mountains}

Fig. 7 shows the February-July mean temperature of Zhouqu since 1650 and its estimated uncertainty range (Briffa et al., 2002; Esper et al., 2007). The mean of February-July temperature over the period AD 16502006 is $15.3^{\circ} \mathrm{C}$. The years $1704\left(13.7^{\circ} \mathrm{C}\right)$ and 1726 $\left(16.8^{\circ} \mathrm{C}\right)$ were reconstructed as the most extreme years. Cool periods with below-average temperature occurred in AD 1674-1681, 1697-1721, 1742-1751, 1766-1773, 1785-1797, 1813-1827, 1838-1850, 1861-1870, 19081923 and 1967-1995. Among those intervals, AD 16971721 witnessed the most severe and extended cool episode in Zhouqu over the past 357 years. Regional warm conditions during AD 1650-1673, 1682-1696, 17221741, 1752-1765, 1774-1784, 1798-1812, 1828-1837, 1851-1860, 1871-1907, 1924-1966 and 1996-2006.

It is found that both the instrumental (Fig. 8a) and reconstructed temperature series (Fig. 8b) show very similar spatial correlation fields. Spatial correlations between our reconstruction and gridded surface temperature data reveal that our reconstruction is associated with a temperature field north of approximately $28-36^{\circ}$ latitude with a large east-west extension. The highest correlations were evident for central China, especially in the southern Gansu. Over the common period from 1901-2006, significant positive correlations are found with in the Pacific Ocean and the Atlantic Ocean, with highest correlations evident for the North Atlantic Ocean (Fig. 8c). No significant correlations can be seen with the SST in the tropical Indian Ocean.

Low-frequency power peaks were found at $56.9 \mathrm{yr}$ (99\%), $22.3 \mathrm{yr}(99 \%)$, and $11.4 \mathrm{yr}(95 \%)$. High-frequency power peaks were found at $2.9 \mathrm{yr}(95 \%), 2.8 \mathrm{yr}(95 \%)$, $2.6 \mathrm{yr}(95 \%), 2.2 \mathrm{yr}(99 \%)$ and $2.0 \mathrm{yr}(99 \%)$ (Fig. 9). The lower frequencies were not found following the use of 100 -year spline function in standardization.

\section{DISCUSSION}

\section{Growth-climate response}

The radial growth of Abies faxoniana at the timberline in our study area is highly correlated with temperature, rather than with precipitation. At our high elevation site, the limited responses to precipitation also suggest that forest trees are not subjected to much water-deficit stress. Therefore, ring widths respond mainly to temperature. Our chronology revealed significant increase in radial growth under the global warming of late $20^{\text {th }}$ century. The tree-ring data in temperature sensitive regions of the middle and high latitude Asia, southwestern China and Tibetan Plateau also revealed the similar increase (Jacoby et al., 1996; Shao and Fan, 1999; Briffa et al., 1995; Song et al., 2007; Gou et al., 2007; Fan et al., 2008; Wu et al., 2008; Liang et al., 2008; Liang et al., 2009; Fan et al., 2009; Duan et al., 2010) indicating a coeval regional warming.

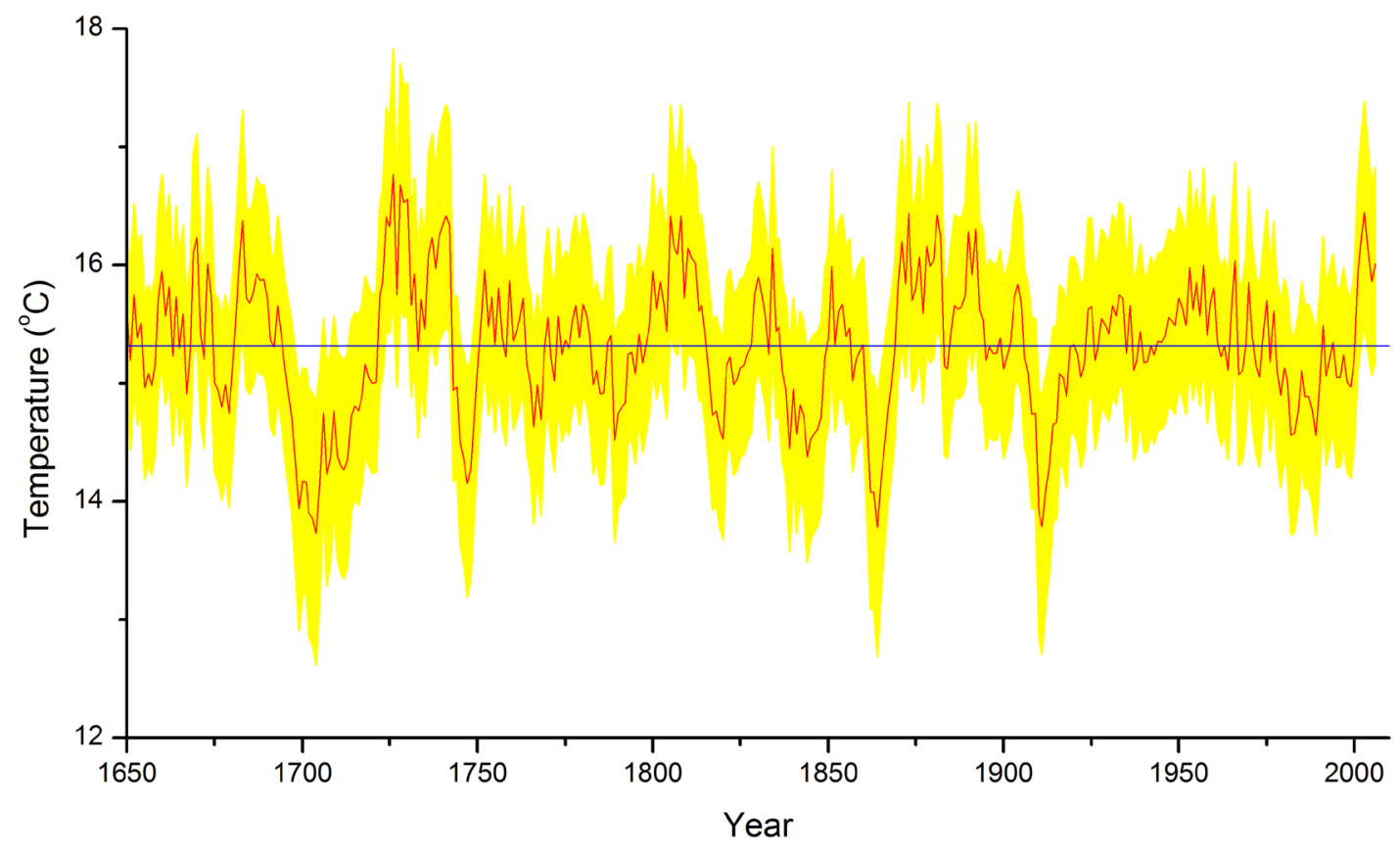

Fig. 7. February-July temperature reconstruction back to 1650 within its estimated uncertainty range. The horizontal line represents the long-term mean of the temperature reconstruction during $1650-2006\left(15.3^{\circ} \mathrm{C}\right)$. 

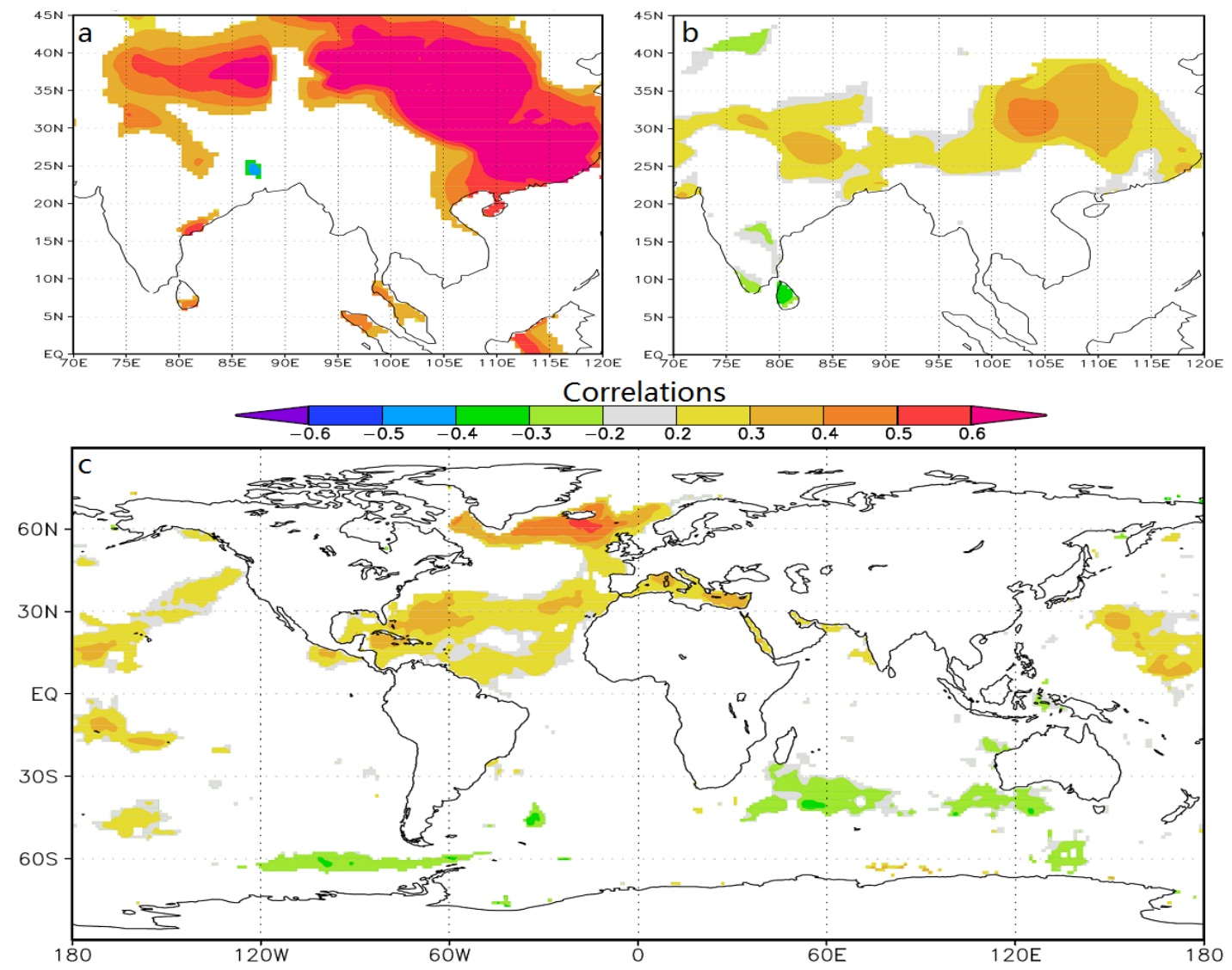

Fig. 8. (a) Spatial correlation fields of instrumental July- mean February-July temperature with the temperature dataset of CRU TS 3.1 for the period 1972-2006. (b) Spatial correlation fields of reconstructed mean February-July temperature with the temperature dataset of CRU TS 3.1 for the period 1901-2006. (c) The reconstructed temperature with the gridded sea-surface temperature (SST) data set of HadlSST1 over their overlapping period from 1900 to 2006. Correlations were calculated after removing the linear trends of data, by using the detrending option of the KNMI Climate Explorer (http://climexp.knmi.nl).

\section{Comparison with regional records}

Spatial correlations (Fig. 8) suggested strong teleconnections between our study areas and High Asia, affected by the regimes of south Asian monsoon. To further investigate the common large-scale temperature signals, we compare our new record with the temperature reconstructions in the surrounding areas (Shao and Fan, 1999; Cook et al., 2003; Wang et al., 2004; Bräuning and Mantwill, 2004; Yadav et al., 2004; Gou et al., 2007; Fan et al., 2008) and a temperature-sensitive tree ring width series (TLD) in Wen County (Wang et al., 2013). The selected series were smoothed with an 10-year low-filter (Fig. 10). The warm period from 1650 to 1673 was detected in Nepal (Cook et al., 2003), West Sichuan (Shao and Fan, 1999). Evidence of the warm period during 1798-1812 was reported from Nepal (Cook et al., 2003), the Western Himalaya (Yadav et al., 2004) northeast Tibet (Gou et al., 2007) and Hengduan Mountains (Fan et al., 2008). The warm period from 1871 to 1907 is consistent with the warm pre-monsoon season in Nepal (Cook et al., 2003) and warm springs in Western Himalaya (Yadav et al.,

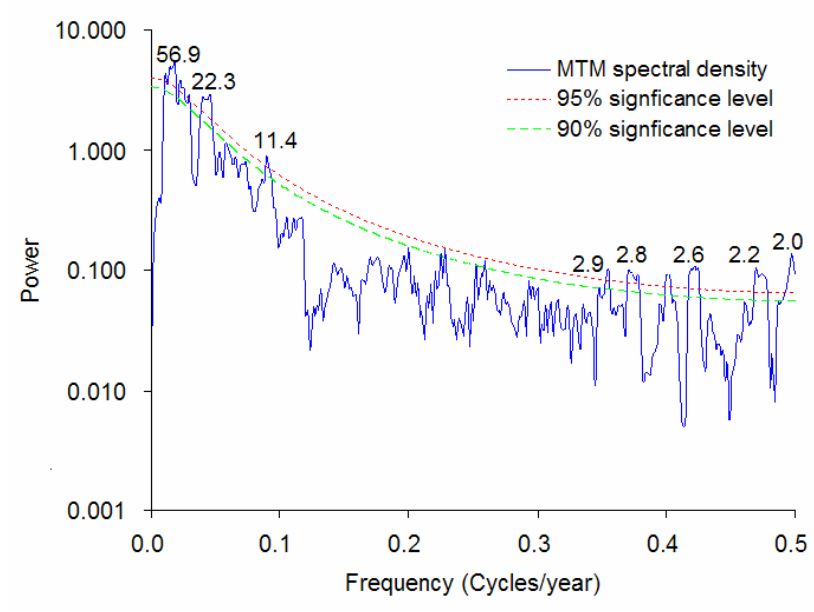

Fig. 9. Results of MTM spectral analysis of the temperature reconstruction of Zhouqu. The dashed and dotted lines indicate the $90 \%$ and 95\% significance level, respectively. 


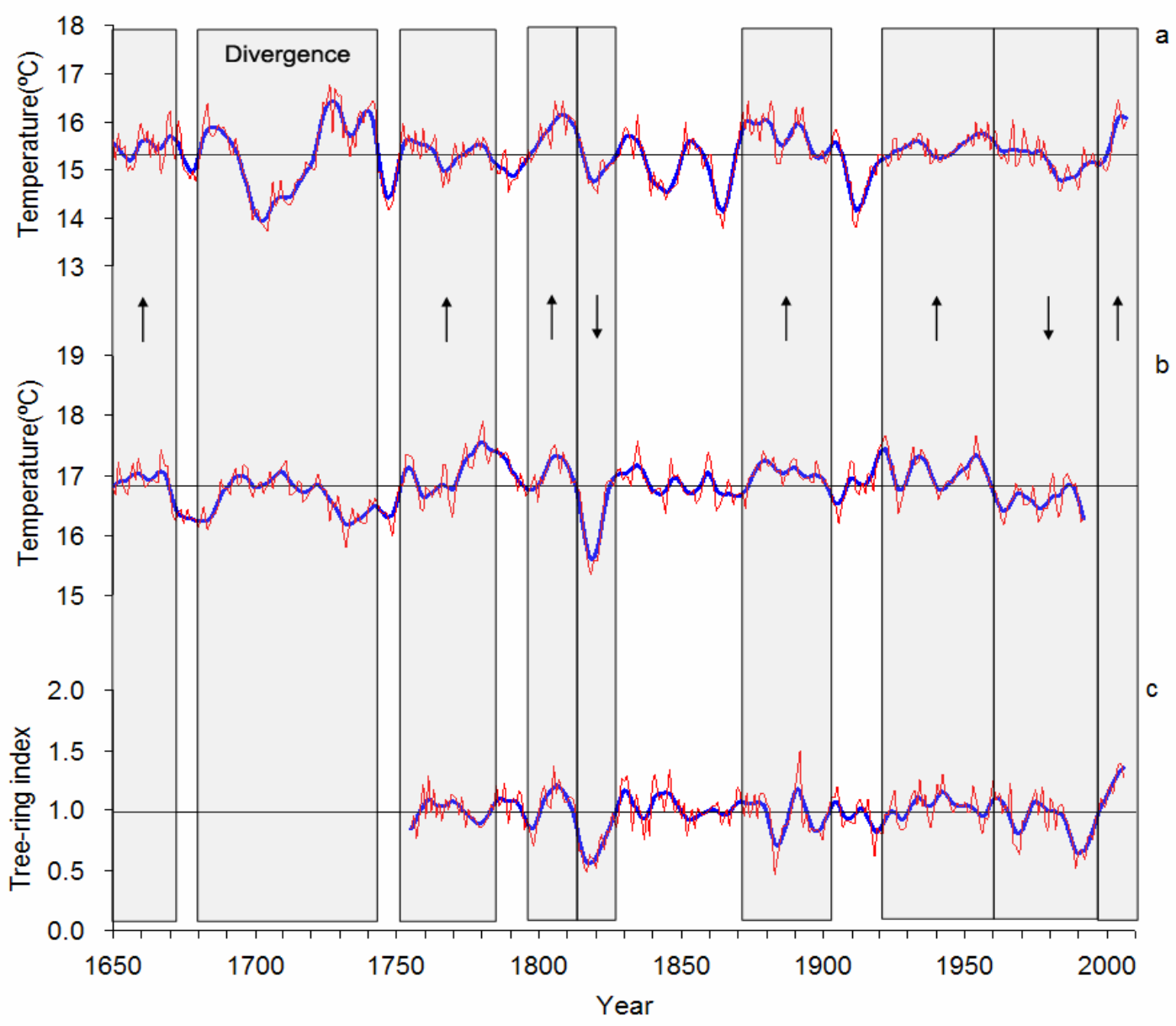

Fig. 10. Comparison of temperature proxy records from different regions. (a) The temperature reconstruction (February-July) of Zhouqu (this study); (b) February-June temperature reconstruction of Nepal (Cook et al., 2003); (c) tree ring width series (TLD) reflecting February-June temperature variations for Wen County (Wang et al., 2013).

2004). Temperature of the western Qinling Mountains was relatively warm during the period 1924-1966. Positive temperature anomalies during the period 1920-1950 in southwestern China were showed by Wang et al. (2004), and were also reported by Fan et al. (2008) and Shao and Fan (1999).

The cold period from 1697 to 1721 was identified for Zhouqu. The coldest year occurred in 1704. This cold period was also reported from the Tibetan Plateau (Bräuning and Mantwill, 2004), the European Alps (Büntgen et al., 2006; Büntgen et al., 2008), Alaska (Davi et al., 2003) and Zajsan Lake area (Chen et al., 2012). This cool period is also found in some Northern Hemisphere reconstructions (Mann et al., 1999; Esper et al., 2002). This may be linked with low solar activity during the Maunder Minimum. However, temperature changes in Zhouqu diverge considerably from the reported for Nepal during 1685-1741 (Fig. 10). Temperature of our study area was relatively low from 1813 to 1827 . This may be linked with a series of tropical eruptions, which likely resulted in an aerosol-accumulated summer cooling effect (Dai et al., 1991; Chenoweth, 2001). The cool period from 1908 to 1923 has also been detected in Hengduan Mountains (Fan et al., 2008) and West Sichuan (Shao and Fan, 1999). The pronounced negative temperatures from 1967 to 1995 in Zhouqu is probably the consequence of enhanced rainfall and thus of increasing monsoon intensity from 1970 to 1990 (Bräuning and Mantwill, 2004).

\section{Spectral analyses and linkages with the Ocean climate variability}

Peaks at 56.9 and $22.3 \mathrm{yr}$ may correspond to similar periods found in the Pacific decadal oscillation (Minobe, 1997, Biondi et al., 2001). The 56.9 yr periodicity resembles other findings in surrounding areas and suggests the influence of solar forcing on South Asian monsoon (Agnihotri et al., 2002). Significant common oscillations between annual sunspot number record and temperature reconstruction were found, except for the two periods 

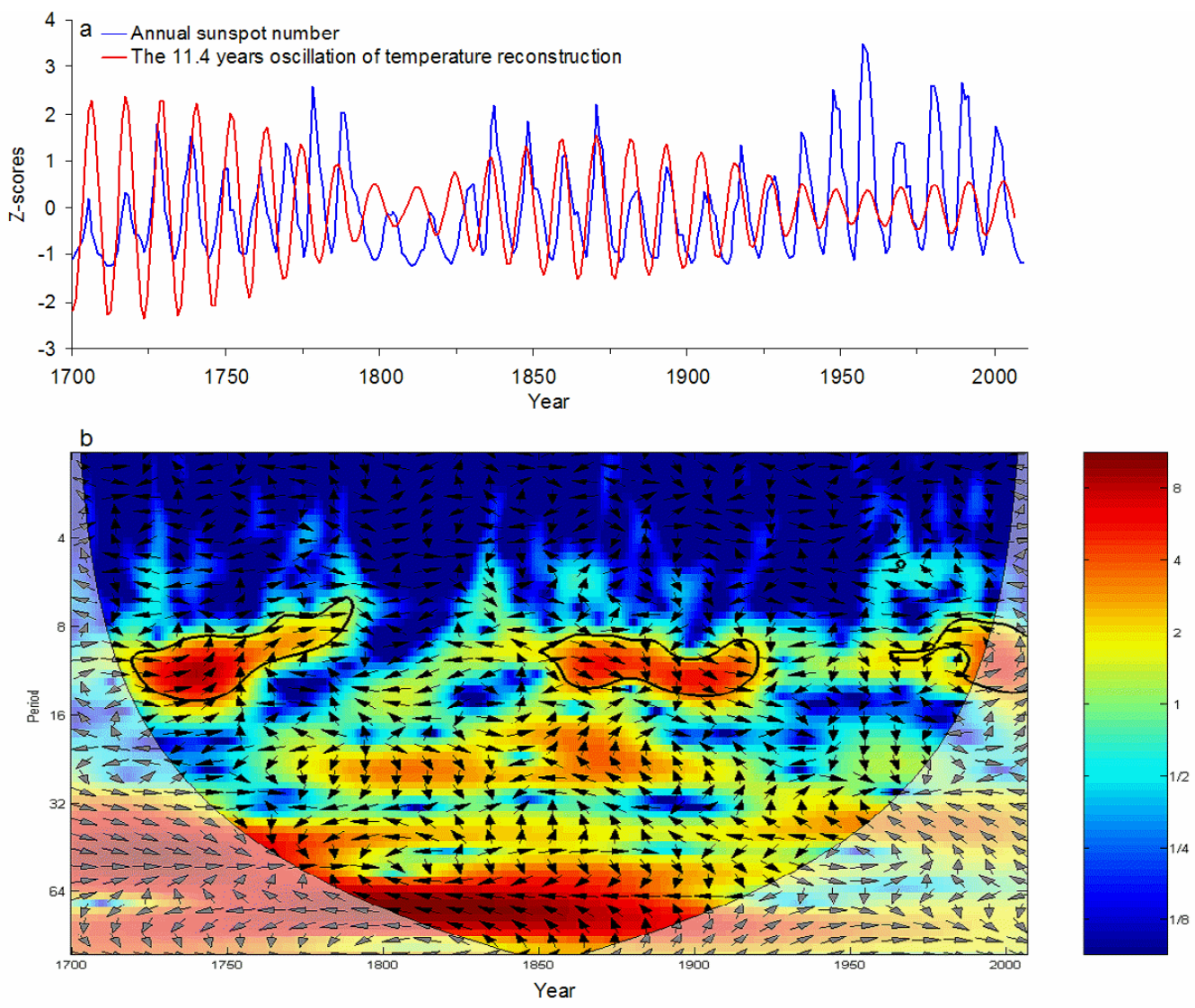

Fig. 11. (a) Visual correlation between annual sunspot number and the 11.4 years oscillation of temperature reconstruction. (b) Squared wavelet coherence between annual sunspot number and our temperature reconstruction. Arrows indicate the phase of the coherence, where right is in phase and left is antiphase; note that significant regions all show an in-phase relationship, which supports the idea that there may be a simple cause and effect relationship between the two phenomena.

(1775-1830 and 1920-1960) (Fig. 11). The cycle may be interrupted by volcanic eruptions during 1775-1830 (Dai et al., 1991; Chenoweth, 2001).

Peaks at 2.0 to $2.9 \mathrm{yr}$ cycles fall within the range of variability of the El Niño-Southern Oscillation and tropical biennial oscillation (TBO) (Allan et al., 1996; Meehl, 1987). Overall, these cycles suggest that our reconstructed temperature variation might have some teleconnections with the oscillations of land-atmospheric-ocean circulation systems. The significant positive correlations of reconstructed temperature with SST in the Pacific Ocean and Arabian Sea fall into the East Asian Monsoon domain (Li and Zeng, 2002), also suggesting a possible link with the Asian Monsoon circulations. Some studies showed that a weakening Asian monsoon observed at the end of the 1970s can be attributed to the decreasing thermal contrast between the Asian continent and the Indian and western Pacific Oceans (Wang, 2001; Li and Zeng, 2002). The precipitation of Zhouqu also shows a decrease trend with increasing temperature trend (Fig. 2b). In addition, a study indicated that the warm-phase of Atlantic Multidecadal Oscillation (the warm SST of the North Atlantic Ocean) causes increases in air temperature in
Eurasia (Wang et al., 2009). The significant positive correlations of the reconstructed temperature with SST in the North Atlantic Ocean were not at odds with such connection. The mechanism how these circulation systems interact awaits further investigation.

\section{CONCLUSIONS}

In this paper, a new tree-ring width chronology was introduced from the western Qinling Mountains, China. February-July temperature is mainly affect the radial growth of trees growing at the timberline of the western Qinling Mountains. A derived linear climate-growth model accounts for $43.5 \%$ of the actual temperature variance (1972-2006). Based on this model, we have reconstructed February-July mean temperatures of Zhouqu in the western Qinling Mountains over the past 357 years. The temperature reconstruction, strongest at capturing the regional climate change signals, identifies ten cooling periods in Zhouqu from 1650 to 2006. Comparison with other tree ring-based temperature reconstructions shows high coherency in the timing of warm/cold episodes, i.e. warm 1650-1673 1871-1907 1924-1966; and cold 1697- 
1721, 1813-1827, 1908-1923, 1967-1995. The spatial correlation patterns with the SST suggest linkages of regional temperature variability with the atmospheric circulations. This record helps broaden the climatic information resource to the Qinling Mountains where heretofore there was little long-term data.

\section{ACKNOWLEDGMENTS}

This work was supported by supported by The Basic Research Operating Expenses of the Central-level Nonprofit Research Institutes (IDM201105), Meteorology Public Welfare Industry Research Special Project (GYHY201106013), NSFC Project (41005059 and 41001115). We thank the reviewers whose comments greatly benefitted this manuscript.

\section{REFERENCES}

Agnihotri R, Dutta K, Bhushan R and Somayajulu BLK, 2002. Evidence for solar forcing on the Indian monsoon during the last millennium. Earth and Planetary Science Letters 198(3-4): 521-527, DOI 10.1016/S0012-821X(02)00530-7.

Alexandersson H, 1986. A homogeneity test applied to precipitation data. Journal of Climatology 6: 661-675, DOI $10.1002 /$ joc. 3370060607 .

Alexandersson H and Moberg A, 1997. Homogenization of Swedish temperature data, Part I: A homogeneity test for linear trends. International Journal of Climatology 17(1): 1001-1013, DOI 10.1002/(SICI)1097-0088(199701)17:1<25::AIDJOC103>3.0.CO;2-J.

Allan R, Lindesay J and Parker D, 1996. El Niño-Southern Oscillation and climatic variability. CSIRO Publishing, Melbourne.

Biondi F, Gershunov A and Cayan DR, 2001. North Pacific decadal climate variability since 1661. Journal of Climate 14(1): 5-10, DOI 10.1175/1520-0442(2001)014<0005:NPDCVS >2.0.CO;2.

Biondi F and Waikul K, 2004. DENDROCLIM2002: A C++ program for statistical calibration of climate signals in tree-ring chronologies. Computers \& Geosciences 30(3): 303-311, DOI 10.1016/j.cageo.2003.11.004.

Blasing TJ, Duvick DN and West DC, 1981. Dendroclimatic calibration and verification using regionally averaged and single station precipitation data. Tree-ring Bulletin 41: 37-43.

Borgaonkar HP, Pant GP and Rupa Kumar K, 1996. Ring-width variations in Cedrus deodara and its climatic response over the western Himalaya. International Journal of Climatology 16(12): 14091422, DOI 10.1002/(SICI)1097-0088(199612)16:12<1409::AIDJOC93>3.0.CO;2-H

Bräuning A and Mantwill B, 2004. Summer temperature and summer monsoon history on the Tibetan plateau during the last 400 years recorded by tree rings. Geophysical Research Letters 31: L24205, DOI 10.1029/2004GL020793.

Briffa KR, Jones PD, Schweingruber FH, Shiyatov SG and Cook ER, 1995. Unusual twentieth-century summer warmth in a 1000-year temperature record from Siberia. Nature 376: 156-159, DOI 10.1038/376156a0.

Briffa KR, Osborn TJ, Schweingruber FH, Jones PD, Shiyatov SG and Vaganov EA, 2002. Tree-ring width and density around the Northern Hemisphere: Part 1, local and regional climate signals. The Holocene 12(6): 737-757, DOI 10.1191/0959683602h1587rp.

Büntgen U, Frank DC, Grudd H and Esper J, 2008. Long-term summer temperature variations in the Pyrenees. Climate Dynamics 31(6): 615-631, DOI 10.1007/s00382-008-0390-x.

Büntgen U, Frank DC, Nievergelt D and Esper J, 2006. Summer temperature variations in the European Alps, AD 755-2004. Journal of Climate 19(21): 5606-5623, DOI 10.1175/JCLI3917.1.
Chen F, Yuan YJ, Wei WS, Fan ZA, Yu SL, Zhang TW, Zhang RB, Shang HM and Qin L, 2013. Reconstructed precipitation for the north-central China over the past 380 years and its linkages to East Asian summer monsoon variability. Quaternary International 283: 36-45, DOI 10.1016/j.quaint.2012.05.047.

Chen F, Yuan YJ, Wei WS, Wang LL, Yu SL, Zhang RB, Fan ZA, Shang HM, Zhang TW and Li Y, 2012. Tree ring density-based summer temperature reconstruction for Zajsan Lake area, East Kazakhstan. International Journal of Climatology 32(7): 1089-1097, DOI 10.1002/joc.2327.

Chen F, Yuan YJ, Wei WS, Yu SL, Li Y, Zhang RB, Zhang TW and Shang HM, 2010. Chronology development and climate response analysis of Schrenk spruce (Picea Schrenkiana) tree-ring parameters in the Urumqi river basin, China. Geochronometria 36: 17-22, DOI 10.2478/v10003-010-0014-4.

Chenoweth M, 2001. Two major volcanic cooling periods derived from global marine air temperature, AD 1807-1827. Geophysical Research Letters 28(15): 2963-2966, DOI 10.1029/2000GL012648.

Cook ER, 1985. A time-series analysis approach to tree-ring standardization. Dissertation, University of Arizona: $171 \mathrm{pp}$.

Cook ER, Anchukaitis KJ, Buckley BM, D'Arrigo RD, Jacoby GC and Wright WE, 2010. Asian Monsoon failure and megadrought during the Last Millennium. Science 328: 486-489, DOI 10.1126/science.1185188.

Cook ER, Krusic PJ and Jones PD, 2003. Dendroclimatic signals in long tree-ring chronologies from the Himalayas of Nepal. International Journal of Climatology 23(7):707-732, DOI 10.1002/joc.911.

Cook E, Shiyatov S and Mazepa V, 1990. Estimation of the mean chronology. In: Cook E and Kairiukstis LA, eds., Methods of Dendrochronology: Applications in the Environmental Sciences. Dordrecht, Kluwer Academic Publishers: 123-132.

Dai J, Thompson EM and Thompson LG, 1991. Ice core evidence for an explosive tropical volcanic eruption 6 years preceding Tambora. Journal of Geophysical Research 96(D9): 17361-17366, DOI 10.1029/91JD01634.

Dang HS, Jiang MX, Zhang QF and Zhang YJ, 2007. Growth responses of subalpine fir to climate variability in the Qinling Mountain, China. Forest Ecology and Management 240(1-3): 143-150, DOI 10.1016/j.foreco.2006.12.021.

Davi N, Jacoby GD and Wiles GC, 2003. Boreal temperature variability inferred from maximum latewood density and tree-ring width data, Wrangell Mountain region, Alaska. Quaternary Research 60(3): 252-262, DOI 10.1016/j.yqres.2003.07.002.

Duan J, Wang LL, Li L and Chen KL, 2010. Temperature variability since A.D. 1837 inferred from tree-ring maximum density of Abies fabri on Gongga Mountain, China. Chinese Science Bulletin 55(26): 3015-3022, DOI 10.1007/s11434-010-3182-8.

Esper J, 2002. 1300 years of climatic history for Western Central Asia inferred from tree-rings. The Holocene 12(3): 267-277, DOI 10.1191/0959683602hl543rp.

Esper J, Cook ER and Schweingruber FH, 2002. Low-frequency signals in long tree-ring chronologies for reconstructing past temperature variability. Science 295: 2250-2252, DOI 10.1126/science. 1066208 .

Esper J, Frank DC, Büntgen U, Verstege A, Luterbacher J and Xoplaki E, 2007. Long-term drought severity variations in Morocco. Geophysical Research Letters 34(17): L17702. DOI 10.1029/2007GL030844.

Fan Z, Bräuning A and Cao KF, 2008. Annual temperature reconstruction in the central Hengduan Mountains, China, as deduced from tree rings. Dendrochronologia 26(2): 97-107, DOI 10.1016/j.dendro.2008.01.003

Fan Z, Bräuning A, Yang B and Cao K, 2009. Tree ring density-based summer temperature reconstruction for the central Hengduan Mountains in southern China. Global and Planetary Change 65(12): 1-11, DOI 10.1016/j.gloplacha.2008.10.001.

Fritts HC, 1976. Tree-Rings and Climate. New York, Academic Press: $567 \mathrm{pp}$.

Fritts HC, Guiot J and Gordon GA, 1990. Verification. In: Cook E and Kairiukstis LA, eds., Methods of Dendrochronology: Applications 
in the Environmental Sciences. Dordrecht, Kluwer Academic Publishers: $178-184$.

Garfin GM, Hughes MK, Liu Y, Burns JM, Touchan R, Leavitt SW and An ZS, 2005. Exploratory temperature and precipitation reconstructions from the Qinling Mountains, Northcentral China. TreeRing Research 61(2): 59-72, DOI 10.3959/1536-1098-61.2.59.

Gou X, Chen F, Jacoby GC, Cook ER, Yang MX, Peng JF and Zhang Y, 2007. Rapid tree growth with respect to the last 400 years in response to climate warming, northeastern Tibetan Plateau. International Journal of Climatology 27(11): 1497-1503, DOI 10.1002/joc. 1480 .

Holmes RL, 1983. Computer-assisted quality control in tree-ring dating and measurement. Tree-Ring Bulletin 43: 69-78.

Hughes MK, 2001. An improved reconstruction of summer temperature at Srinagar, Kashmir since $1660 \mathrm{AD}$, based on tree-ring width and maximum latewood density of Abies pindrow [Royle] Spach. Palaeobotanist 50: 13-19.

Hughes MK, Wu XD, Shao XM and Garfin GM, 1994. A preliminary reconstruction of rainfall in central China since A.D., 1600 from tree-ring density and width. Quaternary Research 42(1): 88-99, DOI 10.1006/qres.1994.1056.

Jacoby GC, D'Arrigo R and Davaajamts T, 1996. Mongolian tree rings and 20th century warming. Science 273: 771-773, DOI $10.1126 /$ science. 273.5276 .771 .

Li J and Zeng Q, 2002. A unified monsoon index. Geophysical Research Letters 29(8): 115-1-115-4 DOI 10.1029/2001GL013874.

Liang EY, Shao XM and Qin NS, 2008. Tree-ring based summer temperature reconstruction for the source region of the Yangtze River on the Tibetan Plateau. Global and Planetary Change 61(3-4): 313-320, DOI 10.1016/j.gloplacha.2007.10.008.

Liang EY, Shao XM and Xu Y, 2009. Tree-ring evidence of recent abnormal warming on the southeast Tibetan Plateau. Theoretical and Applied Climatology 98(1-2): 9-18, DOI 10.1007/s00704008-0085-6.

Liu Y, Linderholm HW, Song HM, Cai QF, Tian QH, Sun JY, Chen DL, Simelton E, Seftigen K, Tian H, Wang R, Bao G and An ZS, 2009. Temperature variations recorded in Pinus tabulaeformis tree rings from the southern and northern slopes of the central Qinling Mountains, central China. Boreas 38(2): 285-291, DOI 10.1111/j.1502-3885.2008.00065.x.

Liu HB and Shao XM, 2003. Reconstruction of early-spring temperature of Qinling Mountains using tree-ring chronologies. Acta Geographica Sinica 58: 879-884 (in Chinese).

Mann ME, Bradley RS and Hughes MK, 1999. Northern Hemisphere temperatures during the past millenium: inferences, uncertainties, and limitations. Geophysical Research Letters 26(6): 759-762, DOI 10.1029/1999GL900070.

Mann ME and Lees J, 1996. Robust estimation of background noise and signal detection in climatic time series. Climatic Change 33(3): 409-445, DOI 10.1007/BF00142586.

Meehl GA, 1987. The annual cycle and interannual variability in the tropical Pacific and Indian Ocean region. Monthly Weather Review 115(1): 27-50, DOI 10.1175/15200493(1987) $115<0027$ :TACAIV>2.0.CO;2.

Minobe S, 1997. A 50-70 year climatic oscillation over the North Pacific and North America. Geophysical Research Letters 24(6):
683-686, DOI 10.1029/97GL00504.

Mitchell TD and Jones PD, 2005. An improved method of constructing a database of monthly climate observations and associated highresolution grids. International Journal of Climatology 25(6): 693712, DOI 10.1002/joc. 1181 .

Osborn TJ, Briffa KR and Jones PD, 1997. Adjusting variance for sample-size in tree-ring chronologies and other regional mean timeseries. Dendrochronologia 15: 89-99.

Preisendorfer RW, 1988. Principal Component Analysis in Meteorology and Oceanography. London, Elsevier: $452 \mathrm{pp}$.

Rayner NA, Parker DE, Horton EB, Folland CK, Alexander LV, Rowell DP, Kent EC and Kaplan A, 2003. A global analyses of sea surface temperature, sea ice, and night marine air temperature since the late nineteenth century. Journal of Geophysical Research 108(D14): 4407, DOI 10.1029/2002JD002670.

Shao XM and Fan JM, 1999. Past climate on west Sichuan plateau as reconstructed from ring-widths of dragon spruce. Quaternary Sciences 1: 81-89 (in Chinese).

Shao XM and $\mathrm{Wu} \mathrm{XD}, 1994$. Tree-ring chronologies for Pinus Armandii Franch from Huashan, China. Acta Geographica Sinica 49: 174-181 (in Chinese).

Song HM, Liu Y, Ni WM, Cai QF, Sun JY, Ge WB and Xiao WY, 2007. Winer mean lowest temperature derived from tree-ring width in Jiuzhaigou Region, China since 1750A.D.. Quaternary Sciences 27: 486-491 (in Chinese).

Torrence C and Compo GP, 1998. A practical guide to wavelet analysis. Bulletin of the American Meteorological Society 79(1): 61-78, DOI 10.1175/1520-0477(1998)079<0061:APGTWA>2.0.CO;2.

Wang H, 2001. The weakening of the Asian monsoon circulation after the end of 1970s. Advances in Atmospheric Sciences 18(3): 376386, DOI 10.1007/BF02919316.

Wang HQ, Chen F, Yuan YJ, Yu SL, Shang HM and Zhang TW, 2013. Temperature signals in tree-ring width chronologies of alpine treeline conifers from the Baishui River Nature Reserve, China. Terrestrial Atmospheric and Oceanic Sciences 24: 887-898, DOI 10.3319/TAO.2013.06.18.01(A).

Wang SW, Zhu JH and Cai JN, 2004. Interdecadal variability of temperature and precipitation in China since 1880. Advances in Atmospheric Sciences 21(3): 307-313, DOI 10.1007/BF02915560.

Wang Y, Li S and Luo D, 2009. Seasonal response of Asian monsoonal climate to the Atlantic Multidecadal Oscillation. Journal of Geophysical Research 114: D02112, DOI: 10.1029/2008JD010929.

Wigley T, Briffa KR and Jones PD, 1984. On the average value of correlated time series, with applications in dendroclimatology and hydrometeorology. Journal of Applied Meteorology and Climatology 23(2): 201-213, DOI 10.1175/15200450(1984)023<0201:OTAVOC $>2.0 . C O ; 2$.

Woodhouse CA, 2003. A 431-yr reconstruction of western Colorado snowpack from tree rings. Journal of Climate 16(10): 1551-1561.

Wu P, Wang LL and Shao XM, 2008. Reconstruction of summer temperature variation from maximum density of alpine pine during 1917-2002 for west Sichuan Plateau, China. Journal of Geographical Sciences 18: 201-210, DOI 10.1007/s11442-008-0201-7.

Yadav RR, Park WK, Singh J and Dubey B, 2004. Do the western Himalayas defy global warming? Geophysical Research Letters 31(17): L17201, DOI 10.1029/2004GL020201. 